\title{
A Necrosis-Inducing Elicitor Domain Encoded by Both Symptomatic and Asymptomatic Plantago asiatica mosaic virus Isolates, Whose Expression Is Modulated by Virus Replication
}

\author{
Ken Komatsu, Masayoshi Hashimoto, Kensaku Maejima, Takuya Shiraishi, Yutaro Neriya, Chihiro Miura, \\ Nami Minato, Yukari Okano, Kyoko Sugawara, Yasuyuki Yamaji, and Shigetou Namba \\ Department of Agricultural and Environmental Biology, Graduate School of Agricultural and Life Sciences, The University \\ of Tokyo, Bunkyo-ku, Tokyo 113-8657, Japan
}

Submitted 7 December 2010. Accepted 14 December 2010.

Systemic necrosis is the most destructive symptom induced by plant pathogens. We previously identified amino acid 1154, in the polymerase domain (POL) of RNA-dependent RNA polymerase (RdRp) of Plantago asiatica mosaic virus (PIAMV), which affects PIAMV-induced systemic necrosis in Nicotiana benthamiana. By point-mutation analysis, we show that amino acid 1,154 alone is not sufficient for induction of necrotic symptoms. However, PIAMV replicons that can express only RdRp, derived from a necrosis-inducing PIAMV isolate, retain their ability to induce necrosis, and transient expression of PIAMV-encoded proteins indicated that the necrosis-eliciting activity resides in RdRp. Moreover, inducible-overexpression analysis demonstrated that the necrosis was induced in an RdRp dose-dependent manner. In addition, during PIAMV infection, necrotic symptoms are associated with high levels of RdRp accumulation. Surprisingly, necrosis-eliciting activity resides in the helicase domain (HEL), not in the amino acid 1,154-containing POL, of RdRp, and this activity was observed even in HELs of PIAMV isolates of which infection does not cause necrosis. Moreover, HEL-induced necrosis had characteristics similar to those induced by PIAMV infection. Overall, our data suggest that necrotic symptoms induced by PIAMV infection depend on the accumulation of a non-isolate specific elicitor HEL (even from nonnecrosis isolates), whose expression is indirectly regulated by amino acid 1,154 that controls replication.

Plant virus infections provoke various responses in host plants, resulting in different disease symptoms. One of the most severe symptoms elicited by plant viruses is systemic necrosis, which can lead to the death of the plant and result in serious crop yield losses. Elucidating the molecular mechanisms of systemic necrosis induction will aid the development of novel strategies for controlling this symptom. Although several symptom determinants of necrosis have been observed in various plant virus genomes, detailed mechanistic descriptions of how they contribute to necrosis in infected plants remain

Corresponding author: S. Namba; Telephone: +8135841 5053; Fax + 81 35841 5054; E-mail: anamba@mail.ecc.u-tokyo.ac.jp

* The $\boldsymbol{e}$-Xtra logo stands for "electronic extra" and indicates that five supplementary figures are published online. elusive (Fernandez et al. 1999; Király et al. 1999; Ozeki et al. 2006; Salánki et al. 2007).

Although the literature on systemic necrosis induced by virus infections in susceptible plants is limited, there are a large number of studies on hypersensitive response (HR), a type of programmed cell death induced by incompatible plantvirus interactions. During $H R$, localized necrotic lesions appear upon recognition of a virus-encoded "elicitor" protein by a respective plant resistance $(R)$ protein complex, which subsequently elicits host defense responses (Kang et al. 2005; Soosaar et al. 2005). Identification of viral HR elicitors, which induce necrosis in host plants carrying an $R$ gene, would greatly facilitate detailed analyses of the molecular mechanisms underlying HR (Erickson et al. 1999; Fellers et al. 2002; Gilardi et al. 2004; Palanichelvam et al. 2000), including elicitor recognition and signal transduction, as well as the development of screens for host factors involved in these steps (Caplan et al. 2008; Rairdan and Moffett 2006).

There is mounting evidence that systemic necrosis triggered by successful virus infection exhibits several features of an $\mathrm{HR}$, and that host factors required for HR induction are also involved in the induction of systemic necrosis (Atsumi et al. 2009; Kim et al. 2008; Komatsu et al. 2010; Seo et al. 2006; $\mathrm{Xu}$ and Roossinck 2000). However, little is known about whether viruses that induce systemic necrosis also code an elicitor protein in their genome, as do HR-inducing viruses. In addition, even when a systemic necrosis pathogenicity determinant is mapped, it remains unclear whether or not the determinant alone can directly induce necrosis, as can an $\mathrm{HR}$ elicitor (Burgyán et al. 2000; Ehrenfeld et al. 2005; Hajimorad et al. 2005; Kagiwada et al. 2005; Kim and Palukaitis 1997; Ozeki et al. 2006; Seo et al. 2009).

Plantago asiatica mosaic virus (PlAMV), a member of the genus Potexvirus in the family Alphaflexiviridae (Komatsu et al. 2008), consists of a single-stranded, positive-sense genomic RNA containing five open reading frames (ORFs). Based on amino acid sequence similarity to other well-studied members of the genus, ORF1 encodes a putative RNA-dependent RNA polymerase (RdRp). ORF2, ORF3, and ORF4 encode movement proteins named triple gene block (TGB) proteins (TGBp1, TGBp2, and TGBp3, respectively). Of these, TGBp1 possesses RNA-silencing suppressor activity (Senshu et al. 2009). ORF5 encodes a coat protein (CP) whose N-terminal region is required for cell-to-cell movement of the virus (Ozeki et al. 2009). PlAMV has been isolated from lily and primrose 
plants in Japan, as well as from Nandina domestica in the United States and Plantago asiatica in Russia. Compared with other virus species in the genus Potexvirus, PlAMV has significantly high genomic variability between isolates (Komatsu et al. 2008).

We previously demonstrated that necrotic symptoms in Nicotiana benthamiana leaves infiltrated with Agrobacterium culture carrying a full-length cDNA clone of the PIAMV isolate Li1 share similar HR characteristics with systemic necrosis induced in a whole plant by the same isolate, and that the host factors known to be involved in HR induction (such as SGT1) are also required for the necrosis (Komatsu et al. 2010). In addition, our previous study of chimeric viruses between necrosis-inducing Li1 and asymptomatic Li6 isolates revealed that amino acid residue 1,154 of RdRp contributes to systemic necrosis (Ozeki et al. 2006). However, how this pathogenicity determinant is linked to necrotic symptoms remains unresolved.

In the present study, using agroinfiltration of different PlAMV constructs into $N$. benthamiana and the estradiolinducible expression system, we identified RdRp as the elicitor of PlAMV-induced systemic necrosis. When transiently expressed, RdRp induced necrosis whether its amino acid 1,154 is cysteine (necrotic Li1-type) or tyrosine (asymptomatic Li6type) in an RdRp dose-dependent manner. Furthermore, the necrosis-eliciting activity of $\mathrm{RdRp}$ resided in its helicase domain (HEL) but not in its polymerase domain (POL) that includes amino acid 1,154 . It is likely that amino acid 1,154 modulates necrotic or asymptomatic symptoms indirectly through its involvement in virus multiplication, which results in changes in the elicitor RdRp expression levels. In addition, we found that HEL-induced necrosis requires host factors involved in HR induction, and has HR-like characteristics similar to those induced by PlAMV infection. Our results suggest that induction of HR-like responses by PIAMV-HEL could be linked to the induction of systemic necrosis in the whole plant, providing new insights into the mechanism through which plant viruses induce systemic necrosis.

\section{RESULTS}

\section{Amino acid 1,154 of the PIAMV-RdRp alone}

\section{does not determine necrotic symptoms.}

We previously reported that amino acid residue 1,154 of PlAMV-RdRp is involved in necrotic symptoms in $N$. benthamiana (Ozeki et al. 2006). Specifically, agroinfiltration-mediated inoculation of isolate PlAMV-Li1 and a single amino acid mutant of isolate Li6 (Li6-1154C), both of which contain cysteine (C) at amino acid position 1,154, results in necrosis in both the infiltrated areas and the upper leaves of $N$. benthamiana. In contrast, Li6 and Li1-1154Y, both of which contains tyrosine (Y) at amino acid position 1,154 , cause no necrotic symptoms, although they can infect the same host systemically (Ozeki et al. 2006). We also observed that amino acid 1,154 is involved in the accumulation of PIAMV but that virus accumulation is not clearly linked to symptom expression (Ozeki et al. 2006). Based on these findings, we hypothesized that amino acid 1,154 could be the direct determinant of necrotic symptoms, perhaps as an elicitor-active site recognized by the host defense system.

To elucidate the mechanism of amino acid 1,154's involvement in producing necrotic symptoms, we introduced noncysteine or nontyrosine mutations into amino acid 1,154 . We designed three mutations: 1154A, which replaced amino acid 1,154 with neutral alanine; $1154 \mathrm{~T}$, with polar threonine; and $1154 \mathrm{~F}$, with the aromatic amino acid phenylalanine. All three mutations were introduced into both Li1 and Li6, resulting in six mutant viruses. Following virus inoculation by agroinfiltra- tion, their symptoms on plants were monitored. $N$. benthamiana plants inoculated with Li1-1154A and Li6-1154A displayed necrotic symptoms similar to Li1 (Fig. 1B). Likewise, both Li1-1154T and Li6-1154T caused necrotic symptoms (Fig. 1A), suggesting that viruses with alanine or threonine, as well as with cysteine, at amino acid 1,154 can induce necrosis with either an Li1 or Li6 genetic background. However, when phenylalanine was introduced into amino acid 1,154, the resultant mutants induced different symptoms depending on genetic backgrounds; plants inoculated with Li1-1154F did not exhibit necrosis, whereas those inoculated with Li6-1154F did (Fig. 1B). Necrotic symptoms induced by amino acid 1,154 with alanine or threonine and by Li6-1154F were accompanied by $\mathrm{H}_{2} \mathrm{O}_{2}$ production detected by diaminobenzedene (DAB) staining (Fig. $1 \mathrm{C}$ and $\mathrm{D}$ ), whereas no $\mathrm{H}_{2} \mathrm{O}_{2}$ production was detected in areas infiltrated with non-necrosis inducing Li1-1154F. All amino acid-1,154 mutants infected the plants systemically, retained their mutated sequences, and produced similar results (necrosis or no symptoms) in the upper leaves of affected plants.

Virus RNA accumulation levels, measured by quantitative reverse-transcription polymerase chain reaction (PCR) in the infiltrated leaves at 3 days postinfiltration, followed earlier observations (Ozeki et al. 2006): substitutions at amino acid 1,154 significantly affected virus RNA accumulation. Although relatively high levels of virus RNA were detected in leaves infected with necrosis-inducing mutants, RNA accumulation of each mutant was not strictly linked to the necrotic phenoltypes (Fig. 1E). Taken together, these results indicate that amino acid 1,154 is not sufficient for the induction of necrotic symptoms. In other words, amino acid 1,154 is unlikely to be an elicitor-active site recognized by the host plant defense system.

\section{Necrotic symptoms induced \\ by PIAMV isolates or replicons are correlated with the expression level of RdRp.}

Because the induction of necrosis is modulated only indirectly by amino acid 1,154 , we next examined which viral factor or factors could directly elicit necrosis in $N$. benthamiana. To this end, we infiltrated $N$. benthamiana plants with Agrobacterium culture that could express each PlAMV-encoded protein. As a result, only the infiltrated area expressing RdRp exhibited necrosis, which was associated with $\mathrm{H}_{2} \mathrm{O}_{2}$ production (Fig. 2A and B). However, transient expression of PlAMVTGBp1, TGBp2, TGBp3, and CP did not induce necrosis in the infiltrated area. Western blot analysis demonstrated that accumulation of the c-myc-tagged TGBp1-3 and CP were detected in the infiltrated leaves, confirming that the absence of necrosis was not due to a lack of protein accumulation (Supplementary Fig. 1).

To further examine the role of ORF1-encoded RdRp in necrosis induction, we prepared an RdRp antibody and assessed the expression level of RdRp in PlAMV-infected plants. The $\mathrm{N}$-terminal 335-amino-acid region containing the methyl transferase domain (MET) of Li1-RdRp was expressed in Escherichia coli, and the purified protein was used to produce an antibody against RdRp, as described by Kakizawa and associates (2001) (Supplementary Fig. 2). Western blot analysis of leaf extracts prepared from PIAMV-infected and uninfected (control) plants revealed a specific protein band of approximately $170 \mathrm{kDa}$ in the pellet fraction (P30) of Li1-infected leaf extract but not in the supernatant fraction (S30) of the same leaf extract. Moreover, this antibody can similarly recognize RdRp of Li6, which exhibits perfect amino acid identity throughout the targeted region (amino acids 1 to 335) with Li1. Using this antibody, we compared the expression of RdRp in leaves infected with each PlAMV variant (Li1, Li6, Li1- 
1154Y, and Li6-1154C). Leaves agroinoculated with necrosisinducing PlAMV (Li1 and Li6-1154C) accumulated increased levels of RdRp compared with non-necrosis inducing viruses Li6 and Li1-1154Y (Fig. 2D, left panels), which is in accordance with their RNA accumulation levels (Fig. 1E). Similarly, high levels of RdRp expression were also detected in the upper uninoculated leaves of necrosis-inducing Li1- or Li6-1154Cinfected $N$. benthamiana plants (Supplementary Fig. 3). These results indicate that, whether in the inoculated or uninoculated leaves, $\mathrm{RdRp}$ accumulation is relatively higher in plants infected with necrosis-inducing viruses than asymptomatic viruses. Overall, these data raise the possibility that the expression level of RdRp could be important for the induction of necrosis.

Next, to further examine the involvement of RdRp expression level in necrosis, we constructed the PIAMV replicon
p53U-RdRp, which contains only ORF1 encoding RdRp and both $5^{\prime}$ and $3^{\prime}$ untranslated regions (UTR) required for replication (Fig. 2C). Northern blot analysis showed that this replicon replicated efficiently (Fig. 3A), in agreement with previous studies showing that RdRp is the only viral protein required for replication in the genus Potexvirus (Komarova et al. 2006; Longstaff et al. 1993). Four PlAMV replicons (53U-RdRp1, 53U-RdRp6，53U-RdRp1-1154Y， and 53U-RdRp6-1154C), derived from each PIAMV variant, were tested for their ability to induce necrosis. Replicons derived from necrosis-inducing variants (53U-RdRp1 and 53U-RdRp6-1154C) caused necrotic symptoms in the infiltrated areas, whereas those derived from non-necrosis inducing variants (53U-RdRp6 and 53U-RdRp1$1154 \mathrm{Y}$ ) caused no symptoms (Fig. 2E). These observations were confirmed by DAB staining, which detected accumula-
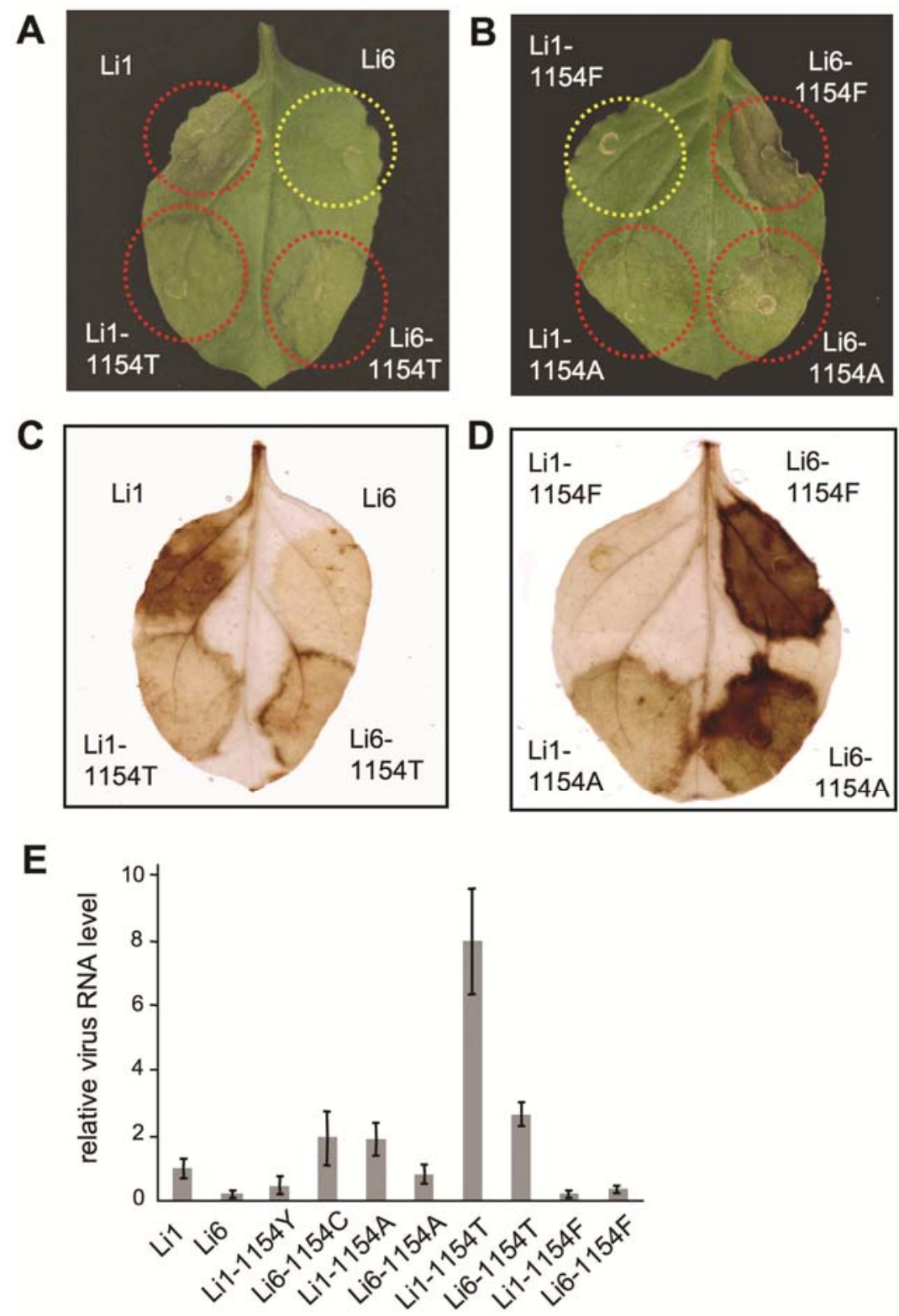

Fig. 1. Amino acid residue 1,154 of RNA-dependent RNA polymerase (RdRp) alone does not determine necrotic symptoms of Plantago asiatica mosaic virus (PlAMV). A and B, Local symptoms on Nicotiana benthamiana leaves infiltrated with Agrobacterium culture carrying binary plasmid for PlAMV infection. Symptoms induced by Li1, Li6, or their mutants with a single amino acid substitution at amino acid 1,154 of RdRp are shown. Red circles indicate necrosis and the yellow circles indicate no necrosis. $\mathbf{C}$ and $\mathbf{D}$, Accumulation of $\mathrm{H}_{2} \mathrm{O}_{2}$ in the leaves shown in A and $\mathrm{B}$, respectively, analyzed by diaminobenzedene staining. Photographs were taken 6 days postinfiltration (dpi) (A through D). E, Accumulation of PlAMV RNA in the infiltrated leaves of $N$. benthamiana. Real-time polymerase chain reaction analysis was performed at 3 dpi using PlAMV coat-protein-specific primers, and the value of PlAMV RNA was normalized relative to the value of EF1A mRNA. Four independent leaves were used for the experiment and mean values (with standard errors) are presented. 
tions of $\mathrm{H}_{2} \mathrm{O}_{2}$ in leaf areas exhibiting necrosis (Fig. 2F). Moreover, RdRp accumulation levels for necrosis-inducing PlAMV replicons were relatively higher than those of non-necrosis inducing replicons (Fig. 2D, right panels), further suggesting a meaningful association between necrotic symptoms and RdRp expression level.

\section{Expression of RdRp protein}

but not its RNA sequence induces necrosis.

The above results do not completely exclude the possibility that replication of PlAMV or accumulation of its RNA is involved in necrosis. Therefore, we examined necrosis-inducing ability and $\mathrm{RdRp}$ accumulation of nonreplicating $5 \mathrm{U}$ -
A

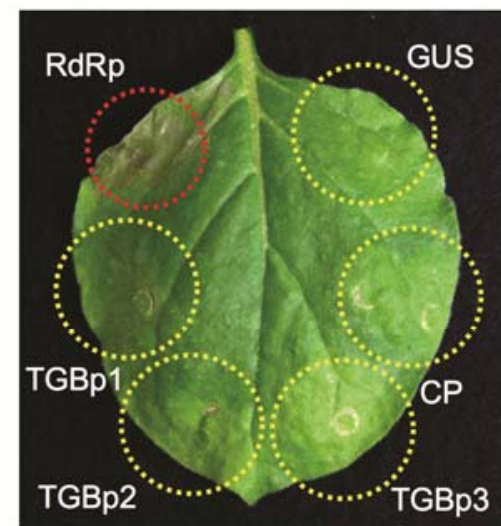

B

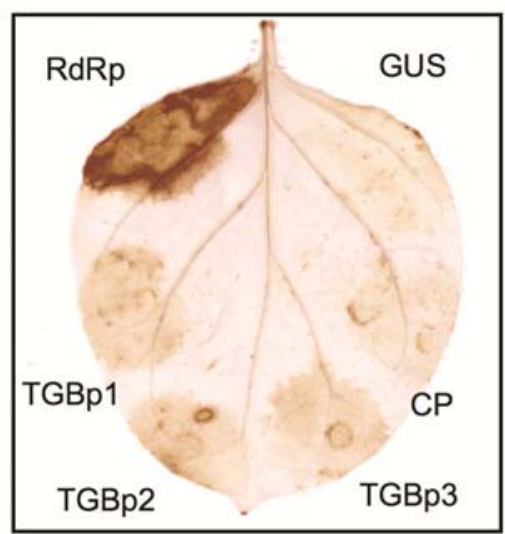

C pLi1

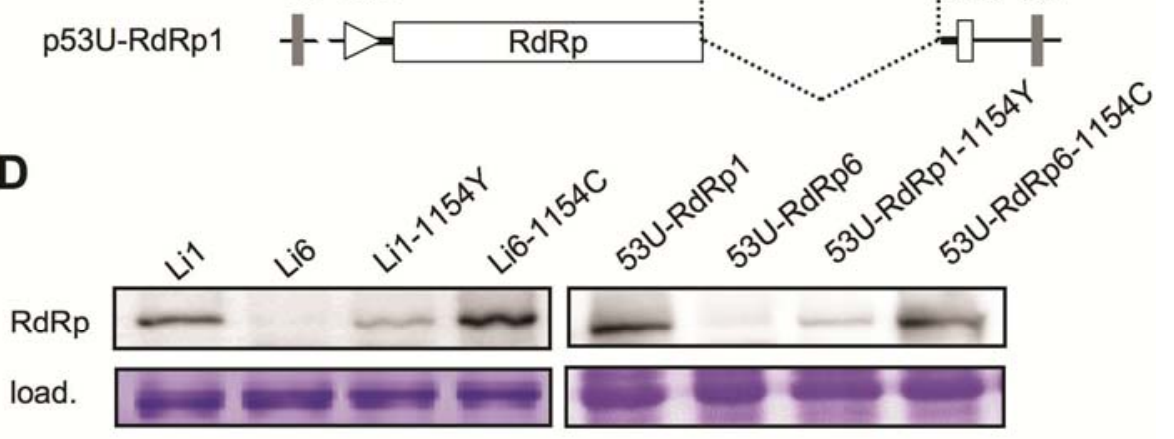

E
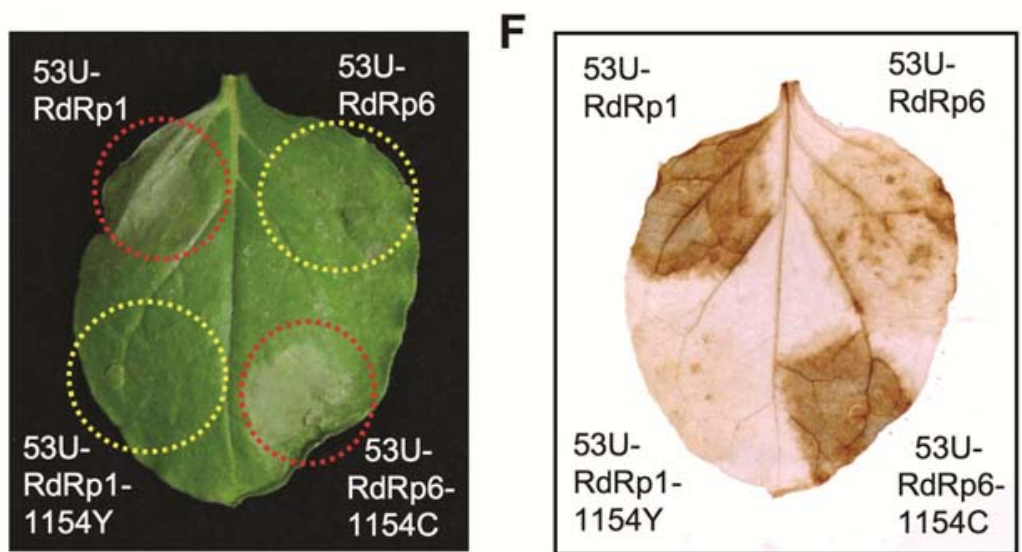

Fig. 2. Necrotic symptoms induced by Plantago asiatica mosaic virus (PlAMV) isolates or replicons are correlated with the expression level of RNA-dependent RNA polymerase (RdRp). A, Local symptoms on Nicotiana benthamiana leaves infiltrated with Agrobacterium culture expressing each PlAMV-encoded protein. Each protein is co-expressed with silencing suppressor p19, both under the control of the 35S promoter. An Agrobacterium culture containing pCAMBIA1301, which expresses $\beta$-glucuronidase (GUS) in the infiltrated area, is used as a negative control. Photographs were taken at 6 days postinfiltration (dpi). Red circles indicate necrosis and yellow circles indicate no necrosis. B, Accumulation of $\mathrm{H}_{2} \mathrm{O}_{2}$ in the leaves shown in A analyzed by diaminobenzedene (DAB) staining. C, Schematic representation of PIAMV cDNA constructs based on the pCAMBIA1301 binary vector. Open boxes represent open reading frames (ORFs). pLi1 contains full-length cDNA of Li1 isolate of PlAMV between the Cauliflower mosaic virus 35S promoter (35S) and the Nos terminator (nos). The boxes labeled with LB and RB represent the left and right border of the T-DNA sequence, respectively. p53U-RdRp1 (designated as replicon in the text) lacks ORF2 to -5 that are not essential for RNA replication but retains the $5^{\prime}$ and $3^{\prime}$ untranslated region of pLi1. D, Accumulation of $\mathrm{RdRp}$ in leaves infiltrated with Agrobacterium culture expressing PlAMV isolates or mutants (left) or each PlAMV replicon (right). A crude membrane (pellet) fraction extracted from the agroinfiltrated leaves was detected by Western blot analysis using anti-RdRp (amino acids 1 to 335) antibody. Coomassie Brilliant Blue staining of the gel is shown as a loading control. E, Local symptoms on N. benthamiana leaves infiltrated with Agrobacterium culture expressing each replicon derived from different PIAMV isolates or mutants. Photographs were taken at 6 dpi. Red circles indicate necrosis and yellow circles indicate no necrosis. $\mathbf{F}$, Accumulation of $\mathrm{H}_{2} \mathrm{O}_{2}$ in leaves shown in $\mathrm{E}$ analyzed by DAB staining. 
RdRp1 (derived from 53U-RdRp1) and its frameshift mutant, 5U-RdRp1-fs. Failure to detect minus-strand genomic RNA from 5U-RdRp1-infiltrated areas indicates that, unlike 53URdRp1, 5U-RdRp1 did not replicate, likely due to the lack of 3' UTR (Fig. 3A). Nevertheless, 5U-RdRp1 induced necrosis that is associated with $\mathrm{H}_{2} \mathrm{O}_{2}$ accumulation in infiltrated areas when co-expressed with the p19 silencing suppressor (Fig. 3B and $\mathrm{C}$ ), whereas 5U-RdRp1 expression alone, as well as ex- pression of p19 alone, did not induce necrosis. This p19-mediated necrosis induction by $5 \mathrm{U}-\mathrm{RdRp} 1$ was consistent with increased RdRp accumulation in infiltrated areas (Fig. 3D). In contrast, 5U-RdRp1-fs, which does not express RdRp due to the frameshift mutation located immediately downstream of the ORF1 initiation codon, induced neither necrosis nor $\mathrm{H}_{2} \mathrm{O}_{2}$ accumulation in infiltrated areas even when co-expressed with p19 (Fig. 3B and C). These results were substantiated by West-
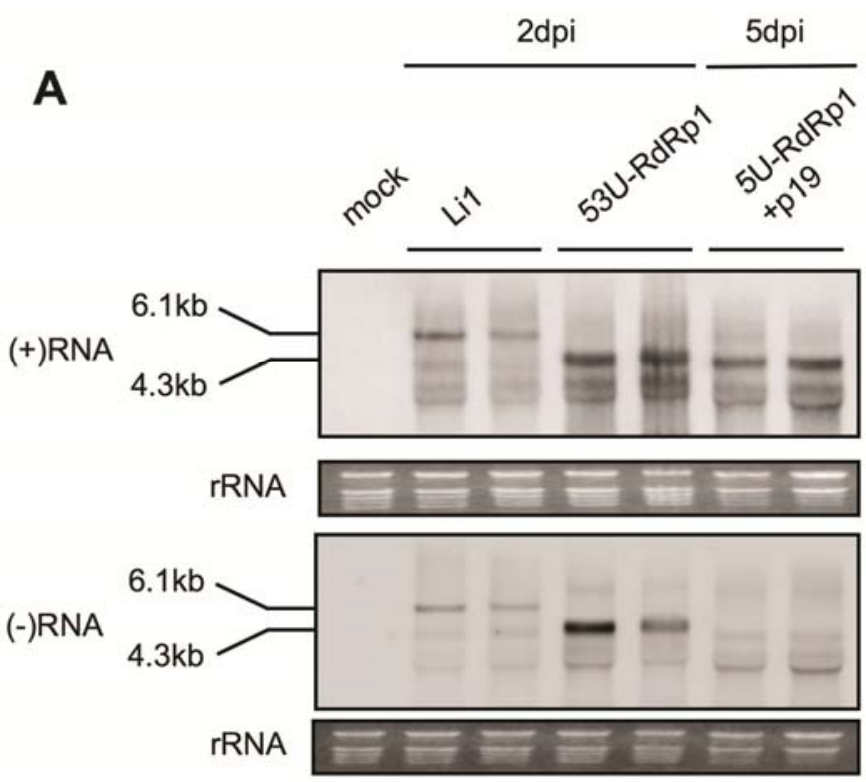

B
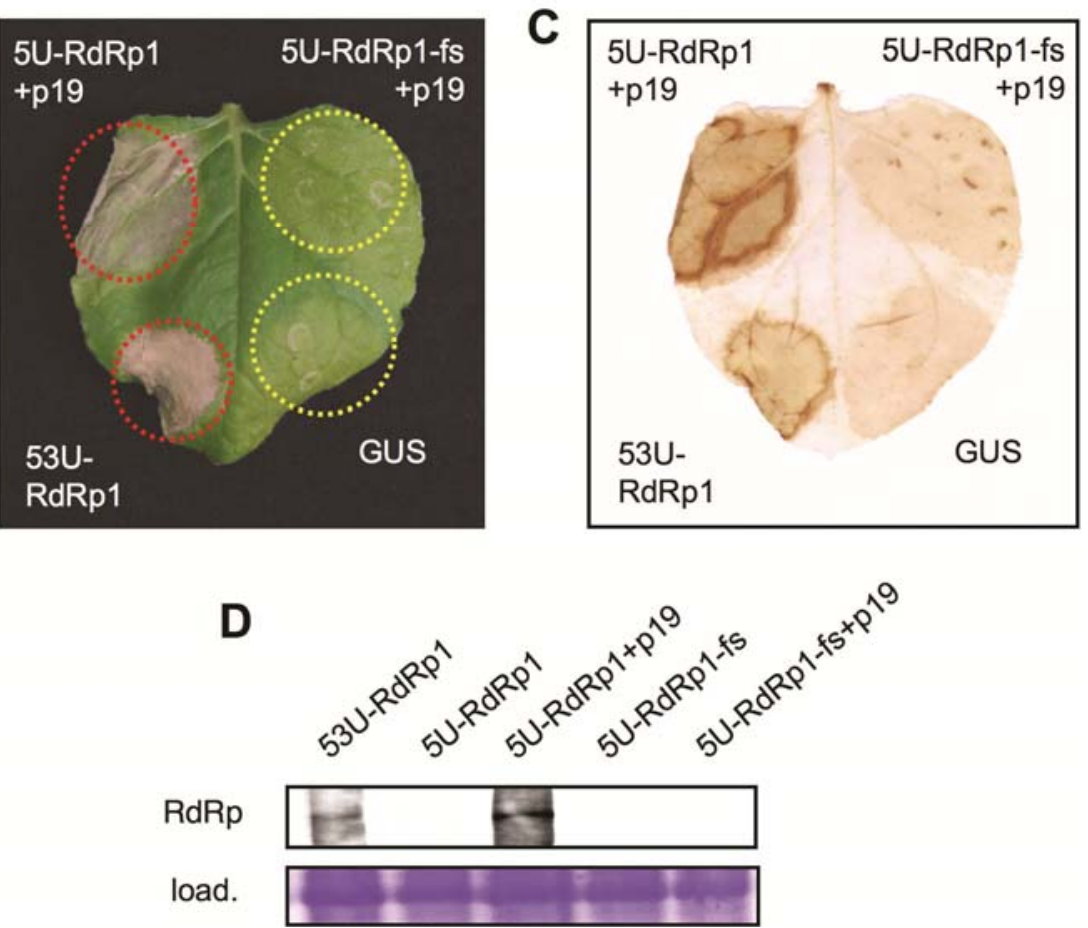

Fig. 3. Expression of RNA-dependent RNA polymerase (RdRp) protein but not its RNA sequence induces necrotic symptoms on Nicotiana benthamiana. A, Northern blot analysis of RNAs accumulated in the leaves infiltrated with Agrobacterium culture expressing either Li1, 53U-RdRp1, or a mixture of 5URdRp1 + p19. Northern blot analyses were performed at the days indicated on the top of the figure, using strand-specific probes to detect positive- or negative-strand Plantago asiatica mosaic virus (PlAMV) genomic RNAs as indicated on the left. Ethidium bromide staining of ribosomal RNA (rRNA) was used as the loading control. B, Local symptoms on $N$. benthamiana leaves infiltrated with Agrobacterium culture containing T-DNA constructs used for transient expression of RdRp. An Agrobacterium culture containing pCAMBIA1301, which expresses $\beta$-glucuronidase (GUS) in the infiltrated area, is used as a negative control and that containing p53U-RdRp as a positive control. Photographs were taken at 6 days postinfiltration (dpi). Red circles indicate necrosis and yellow circles indicate no necrosis. C, Accumulation of $\mathrm{H}_{2} \mathrm{O}_{2}$ in leaves shown in B analyzed by diaminobenzedene staining. D, Accumulation of RdRp in leaves infiltrated with Agrobacterium culture containing each RdRp expression vector. Western blot analysis was performed using anti-RdRp antibody, and Coomassie Brilliant Blue staining of the gel is shown as a loading control. 
ern blot analysis showing minimal detection of RdRp even when 5U-RdRp1-fs was co-expressed with p19 (Fig. 3D). These results demonstrate that the necrosis is associated with high levels of RdRp protein accumulation but not viral RNA accumulation.

\section{Necrosis in $N$. benthamiana is induced in an RdRp dose-dependent but not an amino acid 1,154-dependent manner.}

Because our results indicated that expression of Li1 RdRp alone could induce necrotic symptoms, we posited that the inability of Li6 and Li1-1154Y to induce necrosis in the context of natural infection might be due to their relatively low RdRp expression levels compared with Li1 and Li6-1154C (Fig. 2D). We tested this by overexpressing RdRp of both necrosis-inducing and asymptomatic viruses and by comparing their elicitor activities and expression levels. To this end, we employed an estradiol-inducible expression system (Zuo et al. 2000), which can control the expression level of a desired gene. This system enabled us to reproducibly overexpress $\mathrm{RdRp}$ and to exclude the effect of virus replication on RdRp expression level. RdRps of four PlAMV variants were cloned into the estradiol-inducible vector pER8 (to construct pER8RdRp1, pER8-RdRp6, pER8-RdRp1-1154Y, and pER8-RdRp6$1154 \mathrm{C}$ ), and were co-expressed by agroinfiltration with p19 that enhances expression of a co-expressed gene. To increase the sensitivity of RdRp detection by Western blotting, each RdRp was triple c-myc-tagged at its $\mathrm{C}$ terminus. Estradiolinduced transient expression of RdRp, derived from all four virus variants, induced necrosis as well as $\mathrm{H}_{2} \mathrm{O}_{2}$ production in infiltrated areas, whereas expression of green fluorescent protein by the same system at the same estradiol concentration $(50 \mu \mathrm{M})$ did not (Fig. 4A and B). Western blot analysis of the leaf tissues indicated that, except for Li6-1154C, RdRp derived from the PIAMV variants accumulated at similar levels (Fig. 4C). Northern blot analysis of the same tissues showed a similar level of RNA accumulation for four RdRp expression vectors (Fig. 4C), indicating that RdRp6-1154Y could be less stable or was rapidly degraded. Overall, this suggests that RdRps of all four PlAMV variants have the potential to elicit necrosis when overexpressed at similar levels.

To investigate whether necrosis was induced in an $\mathrm{RdRp}$ dose-dependent manner, we treated leaves with a series of estradiol concentrations following coexpression of pER8RdRp1 and p19. Necrosis was more evident in leaf areas infiltrated with a higher concentration of estradiol (Fig. 4D). DAB staining of leaves indicated that $\mathrm{H}_{2} \mathrm{O}_{2}$ levels were also correlated with the estradiol concentrations (Fig. 4E). To check whether RdRp expression was correlated with estradiol concentration, we harvested leaf tissue samples from agroinfiltrated areas before the appearance of necrosis and performed Western blot analysis using the c-myc antibody. As expected, significantly larger amounts of RdRp were detected with increasing concentrations of estradiol (Fig. 4F).

To test whether an asymptomatic PIAMV isolate can cause necrosis in the context of natural infection, we co-infiltrated Li6 with p19 in $N$. benthamiana. We found that necrotic symptoms were observed when Li6 was co-infiltrated with p19 but not when Li6 alone was infiltrated. Similar necrosis was observed when replicon 53U-RdRp6, which can replicate but only express RdRp, was co-infiltrated with p19 (data not shown), whereas 53U-RdRp6 alone caused no symptoms (Fig. 2E). Moreover, this Li6-induced necrosis caused by the p19 co-infiltration was associated with significant increase in RdRp expression level, suggesting that Li6 can cause necrosis when it expresses increased amounts of $\mathrm{RdRp}$ as a result of p19-mediated efficient multiplication (Supplementary Fig. 4).
Taken together, these findings demonstrate that RdRp encoded by PIAMV has the potential to induce necrosis in $N$. benthamiana when overexpressed, whether its amino acid 1,154 is Cys (Li1 and Li6-1154C) or Tyr (Li6 and Li1-1154Y).

\section{Necrosis-triggering domain resides in the HEL of PIAMV RdRp.}

RdRp of viruses in the genus Potexvirus contains three domains (Fig. 5A), MET, HEL, and POL (Martelli et al. 2007; Yamaji et al. 2001). All of them are also conserved in PlAMV RdRp (Komatsu et al. 2008). To determine which of these domains is important for the RdRp-induced necrosis, a series of constructs for transient expression of each domain, which were c-myc-tagged at the $\mathrm{C}$ terminus, were made using Li1 cDNA as the PCR template. Both 5' and 3' UTR sequences of the virus, which can act as translation enhancers (Gallie 1998; Zelenina et al. 1992), were added to increase expression. Agrobacterium culture containing each of these domain expression constructs was co-infiltrated with p19 into $N$. benthamiana leaves, and symptoms were monitored 6 days after infiltration.

Transient expression of neither the MET nor POL domains of Li1 (MET1 or POL1) triggered necrosis, indicating that these domains do not contribute to RdRp-induced necrosis (Fig. 5A). Consistent with this, DAB staining of leaf areas infiltrated with MET or POL did not produce $\mathrm{H}_{2} \mathrm{O}_{2}$ (Fig. 5A). Interestingly, expression of Li1 HEL (HEL1) induced necrosis that was visible approximately 4 days after infiltration. Meanwhile, transient expression of METHEL1 and HELPOL1 (larger proteins composed of two domains, including HEL1) exhibited delayed and weaker necrosis compared with that induced by HEL1 alone. These results were confirmed by DAB staining of infiltrated leaves (Fig. 5A) and by quantification of cell death extent by ion leakage analysis (Fig. 5B), both of which indicated that expression of HEL-containing proteins significantly induced necrosis in leaves. Western blot analysis using the c-myc-tag antibody showed that all c-myc-fusion proteins were detectable in affected leaves (Supplementary Fig. 5A), indicating that the absence of necrosis induction upon MET or POL expression was not due to protein instability.

In the HEL-coding region, there were only two amino acid differences between necrosis-inducing Li1 and asymptomatic Li6. When we transiently expressed HEL derived from Li6 (HEL6), the leaf areas expressing HEL6 also exhibited necrosis and $\mathrm{H}_{2} \mathrm{O}_{2}$ accumulation (Fig. 5A). HEL derived from an isolate, PlAMV-Pr, which exhibits an overall nucleotide identity of $91 \%$ with Li1 and Li6 isolates (Komatsu et al. 2008), also induced necrosis. Thus, it is likely that HEL of PlAMV can elicit necrosis in $N$. benthamiana independent of the virus isolate from which the domain is derived.

Because we unexpectedly identified HEL, not POL (which contains the previously mapped pathogenicity determinant amino acid 1,154), as an elicitor of PlAMV-induced necrosis, we reasoned that the involvement of amino acid 1,154 in necrosis may be indirect, possibly related to structural changes or masking of elicitor HEL modulated by this residue. Hence, to establish the role of amino acid 1,154 in necrosis induction, we examined whether tyrosine at amino acid 1,154, the amino acid that contributes to an asymptomatic phenotype of Li6 isolate in the context of natural infection, can suppress HEL-mediated necrosis. Surprisingly, both HELPOL6 and HELPOL1$1154 \mathrm{Y}$ (derived from Li6 and Li1-1154Y, respectively) induced necrosis similar to HELPOL1 (Fig. 5A). This result shows that amino acid 1,154 of PlAMV RdRp does not affect HEL elicitor activity through a conformational change of the RdRp or by masking elicitor HEL.

We next examined whether necrosis is, indeed, induced by expression of an HEL protein, not by expression of its RNA. A 
frameshift mutation was introduced after the initiation codon of HEL of p53U-HEL1 to construct p53U-HEL-fs, in which translation of the protein was prevented. Leaf areas infiltrated with Agrobacterium culture containing p53U-HEL-fs did not exhibit necrosis, whether or not p19 was co-expressed. North- ern blot analysis of mRNA accumulation extracted from leaf areas expressing HEL-fs, using a probe specific to HEL, detected mRNA amounts similar to those from leaf areas expressing HEL. This confirmed that accumulation of HEL mRNA was not involved in necrosis.
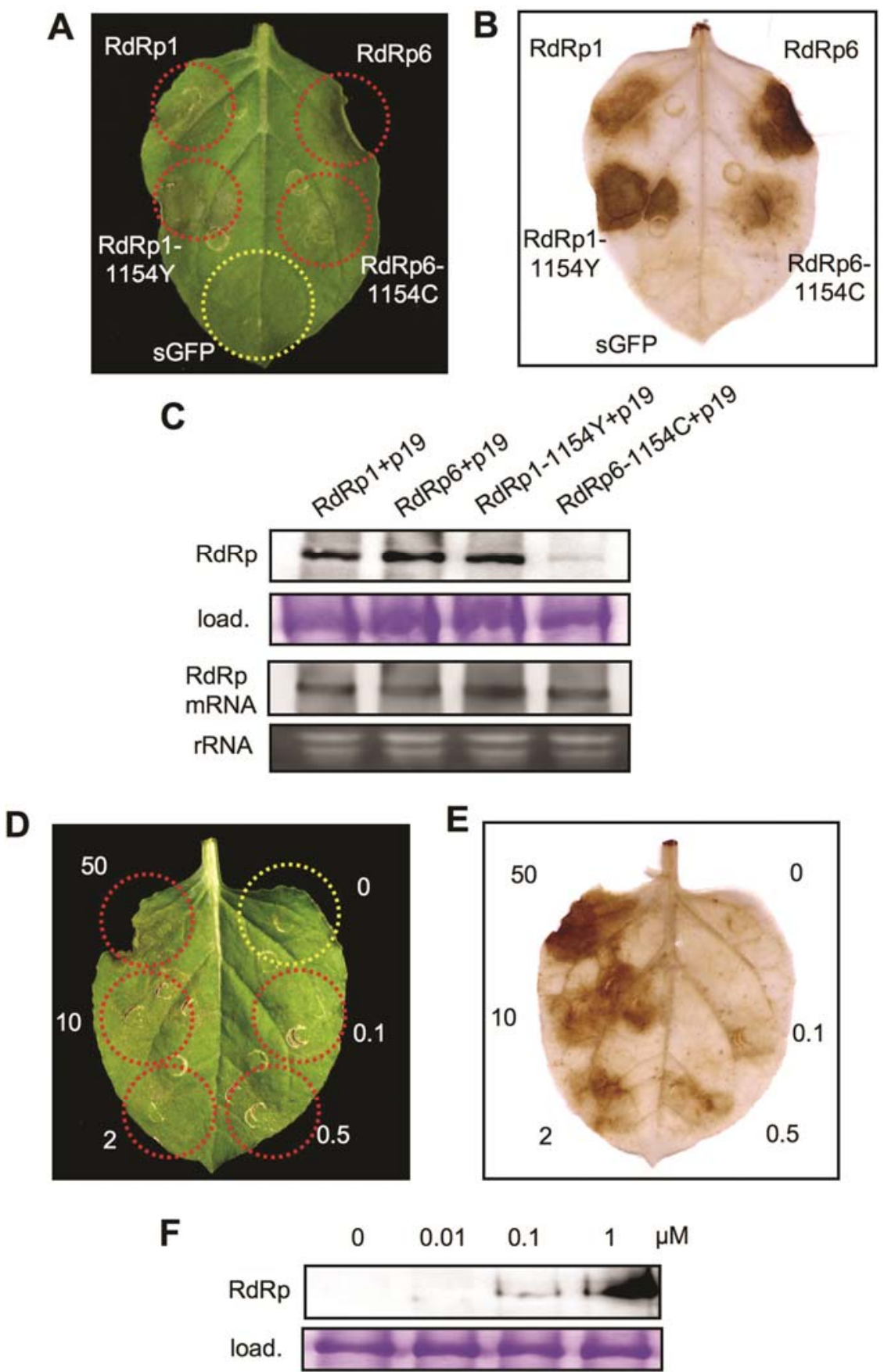

Fig. 4. Necrotic symptoms in Nicotiana benthamiana are induced in an RNA-dependent RNA polymerase (RdRp) dose-dependent but not amino acid 1154dependent manner. $N$. benthamiana leaves were infiltrated with a mixture of two Agrobacterium cultures containing estradiol-inducible RdRp constructs (pER8-RdRp) together with p19. Three days later, leaves were treated with estradiol at the indicated concentrations. A, Local symptoms on N. benthamiana leaves transiently expressing RdRp of four different Plantago asiatica mosaic virus (PlAMV) isolates or mutants by estradiol-inducible system. At 3 days postinfiltration (dpi) of a mixture of Agrobacterium cultures containing p19 and either four pER8-RdRp variants or pER8-sGFP (synthetic green fluorescent protein), estradiol was treated on the same leaves at a concentration of $50 \mu \mathrm{M}$. Red circles indicate necrosis and yellow circle indicates no necrosis. B, Accumulation of $\mathrm{H}_{2} \mathrm{O}_{2}$ of the leaves shown in A analyzed by diaminobenzedene (DAB) staining. C, Accumulation of RdRp and its mRNA in the infiltrated area shown in A. Western blot analysis was conducted using anti-c-myc antibody. Coomassie Brilliant Blue staining as a loading control of Western blot analysis and ethidium bromide staining of ribosomal RNA (rRNA) as the loading control of Northern blot analysis are also shown. D, Local symptoms on $N$. benthamiana leaves expressing different levels of RdRp. N. benthamiana leaves were infiltrated with a mixture of Agrobacterium cultures containing p19 and pER8-RdRp1. Three days later, different levels of estradiol whose concentrations are indicated ( $\mu \mathrm{M})$ were infiltrated in the leaves. Photographs were taken 3 days after estradiol treatment. Red circles indicate necrosis and yellow circle indicates no necrosis. $\mathbf{E}$, Accumulation of $\mathrm{H}_{2} \mathrm{O}_{2}$ in leaves shown in $\mathrm{D}$ analyzed by DAB staining. F, Estradiol dose-dependent RdRp expression assessed by Western blot analysis. Estradiol concentrations ( $\mu$ M) are indicated at the top of the figure. Protein samples were extracted 2 days after estradiol treatment and Western blot analysis was performed as described above. 


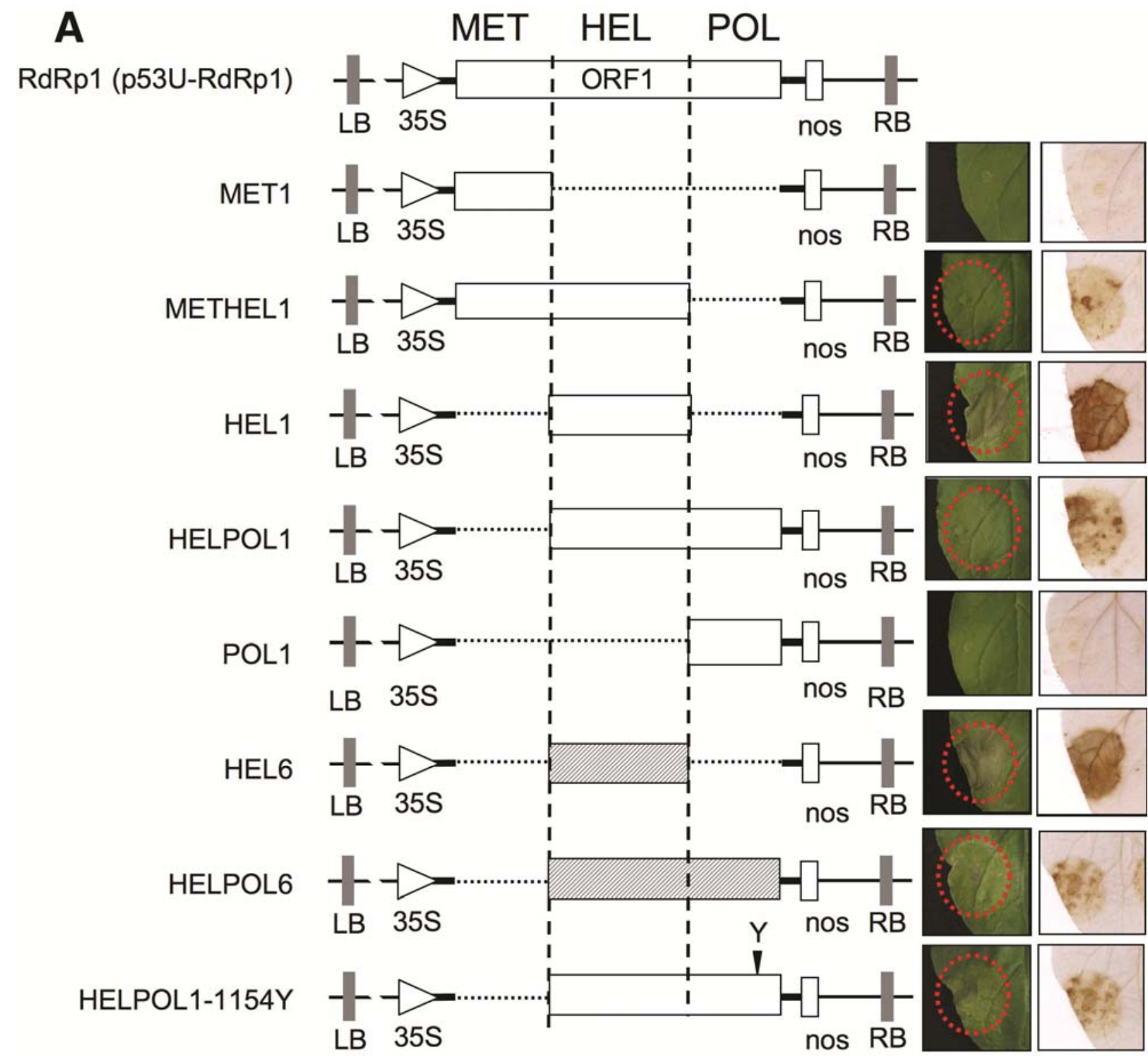

B

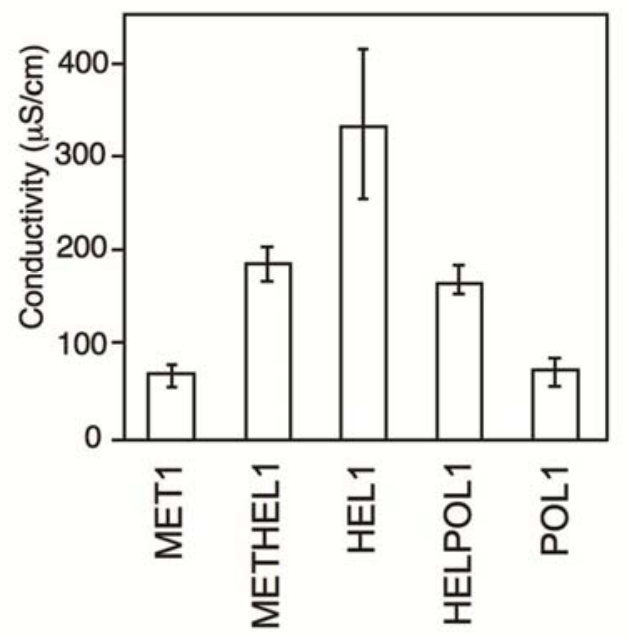

Fig. 5. Necrotic symptom-triggering domain resides in the putative RNA helicase domain (HEL) of Plantago asiatica mosaic virus (PIAMV) RNA-dependent RNA polymerase (RdRp). A, Schematic representation of the constructs used for the transient expression of each domain of PlAMV RdRp and typical symptoms they induced. For simplicity, the prefix p53U was omitted from the plasmid names. PlAMV-Li1 and Li6-derived regions are indicated by blank and hatched boxes, respectively. Local symptoms and $\mathrm{H}_{2} \mathrm{O}_{2}$ accumulation in leaves 6 days postinfiltration with each construct are shown on the right. Red circles indicate necrosis. B, Quantification of cell death in the leaves expressing RdRp domains were derived from Li1 by electrolyte leakage. Error bars represent standard error $(n=5)$. 
Necrotic symptoms induced by HEL have similar characteristics to those induced by PIAMV infection.

We previously noted that systemic necrosis in $N$. benthamiana induced by PlAMV-Li1 requires host factors, such as SGT1, known to be essential for $R$-gene-mediated HR (Komatsu et al. 2010). To test involvement of SGT1 in HEL-triggered necrosis, we used a virus-induced gene silencing approach. $N$. benthamiana plants were inoculated with the Tobacco rattle virus (TRV) vector carrying a partial fragment of NbSGT1 (TV:NbSGT1), while control plants were inoculated with an empty TRV vector (TV:00). HEL1 or Li1 was transiently expressed by infiltration of Agrobacterium culture (containing p53U-HEL1 or pLi1) in the upper leaves of silenced or nonsilenced plants. As expected, HEL1-expressed areas of nonsilenced plants (TV:00) exhibited necrotic symptoms and $\mathrm{H}_{2} \mathrm{O}_{2}$ was detected by DAB staining 6 days after infiltration. In contrast, no necrosis or $\mathrm{H}_{2} \mathrm{O}_{2}$ accumulation was exhibited in HEL1expressed areas of $N b S G T 1$-silenced plants (TV:NbSGT1) (Fig.
6A). As shown previously, Li1-triggered necrosis was compromised in NbSGT1-silenced plants (TV:NbSGT1) compared with control nonsilenced plants (TV:00), suggesting that NbSGT1 expression was indeed knocked down (Fig. 6A). This indicates that, similar to Li1-mediated necrosis, HEL-induced necrosis in $N$. benthamiana requires SGT1.

Our previous study also indicated that MAPKKK $\alpha$, a component of mitogen-activated protein kinase (MAPK) cascades important in many $R$-gene-mediated defense responses, is required for Li1-triggered systemic necrosis (Komatsu et al. 2010). To examine whether MAPKKK $\alpha$ was involved in ne-

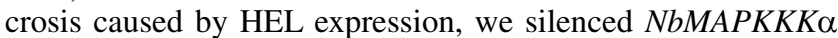
using the TRV vector (TV:NbMAPKKK $\alpha$ ) and then transiently expressed HEL by infiltration. No necrosis or $\mathrm{H}_{2} \mathrm{O}_{2}$ accumulation was induced in HEL1-expressed areas of $N b M A P K K K \alpha$ silenced plants (TV:NbMAPKKK $\alpha$ ) (Fig. 6A), indicating the requirement of MAPKKK $\alpha$ for HEL-induced necrosis in $N$. benthamiana.
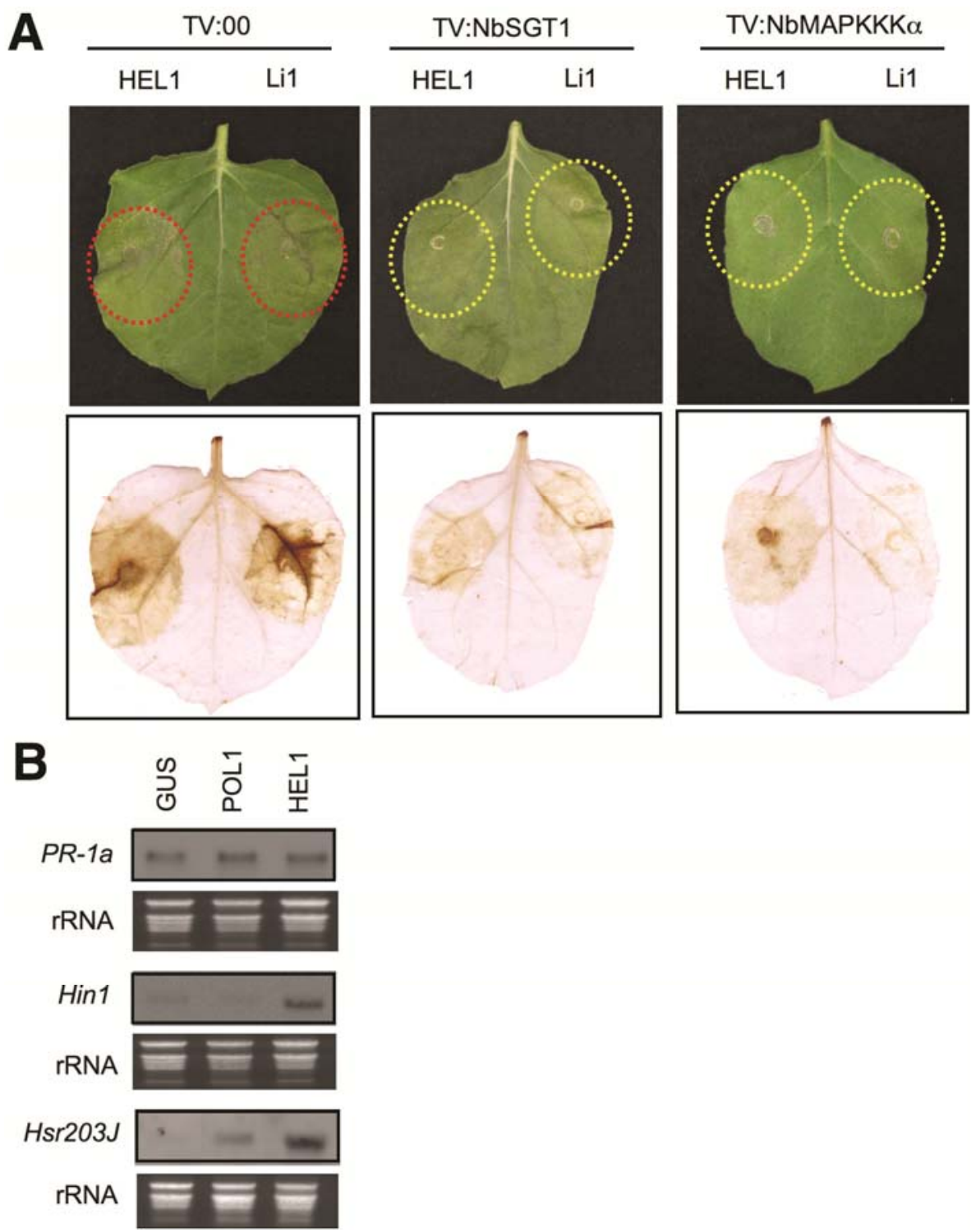

Fig. 6. Necrotic symptoms induced by the helicase domain (HEL) have characteristics similar to those induced by Plantago asiatica mosaic virus (PlAMV). A, Local symptoms (upper panel) and $\mathrm{H}_{2} \mathrm{O}_{2}$ accumulation detected by diaminobenzedene staining (lower panel) of the TV:00 (empty vector), TV:NbSGT1, and TV:NbMAPKKKa-infected Nicotiana benthamiana leaves infiltrated with Agrobacterium culture expressing HEL1 (left half) or Li1 (right half). Photographs were taken at 6 days postinfiltration (dpi). Red circles indicate necrosis and yellow circles indicate no necrosis. B, Northern blot analysis of plant defense-related genes $P R-1 a$, Hinl, and Hsr203J in leaves infiltrated with Agrobacterium containing pCAMBIA1301 ( $\beta$-glucuronidase [GUS]), p53UPOL1 (POL1), or p53U-HEL1 (HEL1). Expression levels of defense-related genes were examined at 3 dpi. Ethidium bromide staining of rRNA confirmed equal loading in each lane. Data shown are representative of three independent experiments. 
To determine whether HEL-induced necrosis, as well as systemic necrosis caused by PlAMV-Li1, is associated with the induction of defense-related genes, we conducted Northern blot analyses using total RNA extracted from $N$. benthamiana leaves infiltrated with Agrobacterium culture expressing $\beta$-glucuronidase (GUS; negative control), POL1, and HEL1. The expression of Hinl and Hsr203J was induced upon transient expression of HEL1 but not upon POL1 and GUS expression (Fig. 6B). Meanwhile, accumulation of $P R-1 a$ mRNA in leaves expressing HEL was comparable with that of leaves expressing the POL domain or GUS. From these results, we conclude that similar mechanisms govern HEL-induced necrosis and systemic necrosis caused by PlAMV-Li1.

\section{DISCUSSION}

The mechanisms underlying symptom expression during virus infection remain poorly understood. Even though a pathogenicity determinant of some plant viruses has been identified, how it induces symptoms in plants has not been fully investigated. In this work, we have identified an elicitor of plant virus-induced systemic necrosis in a genomic region apart from previously mapped pathogenicity determinants. Our findings describe the relationship between necrosis induction by the elicitor and its accumulation level. Using a transient expression system that combined an estradiol-inducible expression vector with agroinfiltration into $N$. benthamiana, we showed that the expression of RdRp of PlAMV induces necrosis in $N$. benthamiana in a dose-dependent manner. The necrosis-triggering activity resides in the HEL of RdRp. It is likely that amino acid 1,154 in the POL of RdRp, previously determined as a pathogenicity determinant that affects systemic necrosis or asymptomatic symptoms, indirectly modulates these symptoms.

HEL-induced necrosis caused several responses whose characteristics were similar to those induced during HR, and it required host factors involved in HR induction (Fig. 6). Our results concur with those of other researchers in suggesting that systemic necrosis displays several characteristics of an HR and that host factors required for HR induction are also involved in the induction of systemic necrosis (Atsumi et al. 2009; Komatsu et al. 2010; Xu and Roossinck 2000). This suggests that systemic necrosis during successful PlAMV infection is an HR-like host defense response triggered by PlAMVHEL, an elicitor of systemic necrosis.

\section{Necrotic symptoms induced \\ by PIAMV depend on RdRp accumulation levels.}

Our findings of an elicitor of PlAMV-induced systemic necrosis have significant implications for understanding the induction mechanism of systemic necrosis. Specifically, our results note the critical role of elicitor accumulation level, not virus multiplication efficiency itself, in the determination of necrotic symptoms. We showed that transient expression of RdRp alone can directly induce necrosis in $N$. benthamiana, and that PlAMV-encoded proteins other than RdRp were not involved in necrosis (Fig. 2A and E). Moreover, our results indicate that, although relatively high virus RNA accumulation was observed in leaves infected with necrosis-inducing mutants, virus replication itself was not required for the induction of necrosis (Figs. 1E and 3B). These data support the possibility that systemic necrosis during PlAMV infection is induced through high-level RdRp accumulation as a result of efficient PlAMV multiplication. This is further supported by results showing that the accumulation level of RdRp of necrosis-inducing PlAMV isolates was higher than that of asymptomatic isolates (Fig. 2D), and that necrosis intensity was correlated with RdRp accumulation in the inducible-expression assay (Fig.
4D). Our previous observations that amino acid 1,154 of PlAMV RdRp affects systemic necrosis or asymptomatic symptoms (Ozeki et al. 2006) can be explained by the amino acid's indirect involvement in the RdRp expression levels.

Other researchers have also noted an elicitor dose dependency for cell death. For example, in $R x$-mediated resistance against Potato virus $X$ (PVX), cell death is not induced under normal infection conditions because extreme resistance (ER) blocks virus accumulation in a single cell, making elicitor $\mathrm{CP}$ accumulation essentially undetectable, whereas transient overexpression of $\mathrm{CP}$ alone in an $R x$-expressing plant elicits cell death (Bendahmane et al. 1999). In $N$-mediated resistance against Tobacco mosaic virus (TMV), cell death appears to be induced by p50 (elicitor of TMV) in an elicitor dose-dependent manner, and enhanced by sequences that promote translation of the elicitor. Conversely, cell death is delayed and weakened when full-length RdRp (that includes p50) is expressed because the elicitor is probably expressed at lower levels than in the case of p50 alone, due to the much higher molecular weight of full-length TMV-RdRp (Abbink et al. 1998; Erickson et al. 1999). These observations, combined with our results, suggest that cell death exhibited in HR, as well as that in systemic necrosis, is generally induced in an elicitor dose-dependent manner.

Our identification of an elicitor of systemic necrosis and demonstration of its dose dependency in necrosis induction indicate that an unidentified elicitor could be involved in systemic necrosis traditionally assumed to be caused by an efficient replication of viruses, whose underlying mechanisms are poorly understood. Future studies investigating elicitor activity of proteins encoded in other systemic necrosis-inducing viruses should address these possibilities.

\section{Role of amino acid 1,154, which controls pathogenicity in elicitor activity.}

Another implication drawn from our results is that a pathogenicity determinant mapped by the analysis of chimeric viruses does not necessarily play a critical role in elicitor activity. Until now, differences between HR-inducing avirulent and non-HR inducing, virulent pathogens in an $R$-gene-carrying plant were assumed to be due to strain-specific amino acid substitutions affecting elicitor activity (Hajimorad et al. 2006; Taraporewala and Culver 1996). Indeed, two amino acid residues in PVX CP are involved in $R x$-mediated resistance against PVX (Goulden et al. 1993). Both amino acids are located in the central core region of the $\mathrm{CP}$ known to affect elicitor activity, indicating that these amino acids induce conformational changes in the $\mathrm{CP}$, resulting in elicitor activity changes (Baurés et al. 2008). Thus, it had been postulated that amino acid 1,154 of PlAMV RdRp, which contributes to systemic necrosis in $N$. benthamiana (Ozeki et al. 2006), is likely directly involved in the elicitation of necrosis by conformational changes in RdRp. Contrary to this assumption, however, we demonstrated that necrosis was induced by transient expression of HEL in an amino acid 1,154-independent manner (Fig. 5, HELPOL1 and HELPOL1-1154Y). This indicates that local changes in RdRp structure by amino acid 1,154 do not play a role in the elicitor activity of HEL.

As discussed above, a major role of amino acid 1,154 in necrosis induction is its involvement in virus replication, which subsequently affects the accumulation levels of the necrosisinducing elicitor HEL. This conclusion is strongly supported by the observation that the level of RdRp accumulation is different between PIAMV isolates or mutants and is correlated with the accumulation of virus RNA during virus infections (Figs. 1E and 2D), whereas the expression level of RdRp derived from different PIAMV variants is similar when tran- 
siently expressed (Fig. 4C). On the other hand, because HEL is always expressed as an integral part of RdRp in PlAMVinfected plants, we cannot entirely exclude the possibility that amino acid 1,154 may moderately affect the HEL expression level through its involvement in the stability of RdRp. Indeed, our observations from transient expression experiments showing that $\operatorname{RdRp}$ with cysteine at position 1,154 has relatively less accumulation than that with tyrosine are consistent with this idea (Fig. 4C). However, viruses that contain cysteine at amino acid 1,154 multiplied efficiently during infection, and resultant RdRp accumulation was relatively higher than for those containing tyrosine at the same residue, although their RdRps are less stable. This indicates that, in the context of natural infection, $\mathrm{RdRp}$ accumulation level modulated by amino acid 1,154 was mainly affected by virus replication efficiency rather than stability of RdRp. It is important in future studies to examine the precise role of amino acid 1,154 in PlAMV replication and any resultant necrosis.

Together with the elicitor dose dependency of necrosis discussed above, our observations that even RdRps encoded by asymptomatic PlAMV isolates have necrosis-inducing activity (Fig. 4A) imply that virus isolates that asymptomatically infect host plants could also encode an elicitor protein that can potentially induce necrosis when overexpressed. This is further supported by the observation that even an asymptomatic Li6 exhibited necrotic symptoms when its replication was enhanced by co-infiltration with $\mathrm{p} 19$. Indeed, the elicitor activity of PIAMVHEL is not isolate specific: HEL derived from the necrosisinducing Li1 isolate, as well as from the asymptomatic isolate Li6, can induce necrosis in $N$. benthamiana leaves (Fig. 5). Interestingly, HEL from the relatively distant PlAMV isolate Pr, which shares approximately $90 \%$ nucleotide sequence identity with $\mathrm{Li}$ isolates (Komatsu et al. 2008), can also induce necrosis. Although we cannot exclude the possibility of the presence of other PlAMV isolates whose HEL does not exhibit necrosisinducing activity in $N$. benthamiana, it is worth considering that elicitor activity of HEL was conserved within the species. Recent findings that the central regions of $\mathrm{CP}$ of five different $\mathrm{Po}$ texvirus spp. trigger $R x$-dependent HR provide a similar example of the conservation of non-isolate specific elicitor activity (Baurés et al. 2008; Candresse et al. 2010). A smaller elicitor domain was identified in the $\mathrm{CP}$ of these potexviruses but low levels of amino acid sequence conservation of this elicitor suggests that a conserved secondary structural element rather than a specific amino acid motif could be targeted by $\mathrm{Rx}$ protein to induce the HR (Baurés et al. 2008). It is also possible that the PlAMV HEL has a conserved secondary structural element, such as that involved in nucleoside triphosphatase (NTPase) and RNA 5'-triphosphatase activities (Han et al. 2007), which could be essential for viral fitness in the host, targeted by host defense systems. Taking into account the fact that host defense responses against viruses are involved in systemic necrosis (Komatsu et al. 2010), it is tempting to speculate that PlAMV evades host antiviral defenses by mutating amino acid 1,154 , which might not be vital for virus survival but indirectly affects elicitor HEL accumulation through its involvement in replication. Modulation of elicitor expression by mutating a replicase and reducing viral multiplication, without mutating the elicitor domain itself, may represent an alternative strategy of viruses for circumventing cell death, one of the host plant defense responses.

\section{Putative mechanisms \\ of the HEL-triggered necrosis induction.}

Our results indicate that HEL was the sole determinant of PlAMV-induced necrotic symptoms in N. benthamiana. Although it is not known precisely how PlAMV-HEL induces necrosis during infection, a likely mechanism may be incomplete gene-for-gene resistance mediated by interactions between HEL and an unidentified host $\mathrm{R}$ protein. In support of this model was the requirement of SGT1, which is known to play essential roles in many $R$-gene-triggered resistance responses against viruses (such as $R x$-mediated resistance to PVX and $N$-mediated resistance to TMV) for HEL-mediated necrosis (Fig. 6A).

Alternatively, the HEL-triggered necrosis may have relevance to an inherent cellular function of HEL, which is important in the PIAMV infection process. Because replication of many positive-strand RNA viruses occurs in association with intracellular membranes, many virus replicase proteins induce a massive modification and proliferation of membranes that support virus replication (Liu et al. 2009; Schaad et al. 1997). Such modification of intracellular membranes can damage the cell and lead to necrosis (Carette et al. 2002; Mochizuki et al. 2009). Recently, it was reported that RdRp of PVX, a member of the same genus as PlAMV, localizes in ER-derived membranes (Bamunusinghe et al. 2009). These findings support the idea that HEL of PlAMV RdRp might have the capacity to cause host membrane rearrangements required for PlAMV replication, and that the aberrant expression of HEL might induce necrosis. Further analyses are needed to understand the cellular behavior of RdRp (and HEL as a part of RdRp) and to characterize their interactions with host proteins responsible for necrosis.

\section{MATERIALS AND METHODS}

\section{Plant material, virus isolates, agroinfiltration, and estradiol treatment.}

$N$. benthamiana plants were grown in a growth chamber at $25^{\circ} \mathrm{C}$. The PlAMV isolates used in this study and their mutant isolates (Li1, Li6, Li1-1154Y, and Li6-1154C) were described previously (Ozeki et al. 2006). Their infection was launched from Agrobacterium T-DNAs using binary plasmids containing full-length PlAMV cDNA clones (pLi1 and $\mathrm{pLi} 6$ for Li1 and Li6 infection, respectively) (Ozeki et al. 2006). All plasmids were transformed into Agrobacterium tumefaciens EHA105 to transiently express proteins by agroinfiltration (Takahashi et al. 2006). When estradiol-inducible constructs were used, a solution of 17- $\beta$-estradiol (Sigma-Aldrich, St. Louis) dissolved in $10 \mathrm{mM} \mathrm{MgCl} 2$ was pressure infiltrated into $N$. benthamiana leaves after agroinfiltration (details can be found in the figure legends).

\section{Plasmid constructions.}

All single amino acid mutant viruses (at amino acid 1,154 of the RdRp) were generated by PCR-based site-directed mutagenesis of pLi1 and pLi6, based on the two-step recombinant PCR approach of Ozeki and associates (2006). The following primers were used for mutagenesis (mutagenized nucleotides are underlined): Pl-1154AF (5'-C TCC CGG TGG GTC CTC AAC GCC TGG GAC TTC TCC AAA CCA T-3') and Pl-1154AR (5'-A TGG TTT GGA GAA GTC CCA $\underline{\text { GGC }}$ GTT GAG GAC CCA CCG GGA G-3') for the mutants with alanine at amino acid 1,154, Pl-1154TF (5'-C TCC CGG TGG

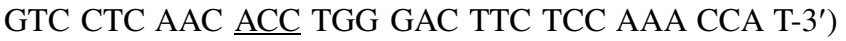
and Pl-1154TR (5'-A TGG TTT GGA GAA GTC CCA GGT GTT GAG GAC CCA CCG GGA G-3') for the mutants with threonine, and Pl-1154FF (5'-C TCC CGG TGG GTC CTC AAC TTC TGG GAC TTC TCC AAA CCA T-3') and Pl1154FR (5'-A TGG TTT GGA GAA GTC CCA GAA GTT GAG GAC CCA CCG GGA G-3') for the mutants with phenylalanine.

To construct the PlAMV replicon p53U-RdRp1, which derives from pLi1, a DNA fragment was PCR amplified from pLi1 using primers Pl-2032F (5'-G CAG ACC AAC CTC 
GCC ATC T-3') and Pl-RDR (5'-A TTT GAT ATC TTA GTC GAC ATC GGA GTT AAG GAA AGA TGA ACC ACC-3'). The PCR fragment was digested with $B g l$ III, followed by ligation into pLi1 using the BglII site and the Klenow-filled SpeI site. p53U-RdRp6, p53U-RdRp1-1154Y, and p53U-RdRp6$1154 \mathrm{C}$ were constructed using each virus isolate or mutant as a template and a vector instead of pLi1.

A DNA fragment, containing 35S promoter, 5' UTR, and ORF1 of PlAMV-Li1, was PCR amplified using primer $35 \mathrm{SXbEcF}$ (5'-TAT TCT AGA GAA TTC AAA CCT CCT CGG ATT CCA TTG-3') and Pl-RDR. The PCR-amplified fragment was digested with $X b a I$ and cloned into pCAMBIA1301 via $X b a I$ and $P m a C I$ (blunt-ended site) restriction sites, yielding p5U-RdRp1. To construct p5U-RdRp1-fs, p5URdRp1 was digested with MunI (nucleotide 304 of Li1), end filled with Klenow fragment, and religated.

For an estradiol-inducible transient expression, an RdRp gene with its $5^{\prime}$ UTR derived from each PlAMV variant was PCR amplified using the primers Pl-1F (5'-GAA AAC AAA CCT ACA CAA ACC A-3') and Li-RDR, digested with XbaI, and cloned into the XhoI (blunt-ended with Klenow fragment) and SpeI sites of a triple c-myc-tagged modified-pER8 vector (K. Komatsu, unpublished data; Zuo et al. 2000).

To generate p53U-MET, -METHEL, -HEL, -HELPOL, and -POL for the transient expression of RdRp domains of PlAMV-Li1, each domain (MET: amino acids 1 to 404; HEL: amino acids 405 to 914 ; and POL: amino acids 915 to 1,380 ) or each of the two consecutive domains (METHEL: amino acids 1 to 914; and HELPOL: amino acids 405 to 1,380) was PCR amplified using the appropriate forward primers with the MfeI site (LiMDF, LiHELF, and LiRDF for the amplification of MET, HEL, and POL regions, respectively) and the corresponding reverse primers containing both the c-myc tag sequence and $X b a \mathrm{I}$ site (LiMDR, LiHELR, and LiRDR for the amplification of MET, HEL, and POL regions, respectively), with pLi1 as a template. To obtain PCR product for the construction of p53U-HEL6 and -HELPOL6, and p53UHELPOL1-1154Y, Li6 and Li1-1154 were used as a template, respectively. The obtained PCR products were purified and digested with $M f e \mathrm{I}$ and $\mathrm{XbaI}$, followed by ligation into $\mathrm{MfeI}$ and SpeI-digested pLi1.

All PCR amplifications were performed using KOD-Plus DNA polymerase (TOYOBO, Osaka, Japan), and all constructs were verified by sequencing.

\section{RNA extraction, Northern blotting, and real-time PCR.}

Total RNA was isolated using ISOGEN (Nippon Gene, Tokyo) and was used for Northern blot analyses using the digoxigenin (DIG) system (Roche Diagnostics, Mannheim, Germany) described by Senshu and associates (2009). Expression of $P R$ la, Hinl, and Hsr203J was analyzed using RNA probes (Komatsu et al. 2010). For plus- and minus-strand virus genome RNA detection, strand-specific DIG-labeled probes were transcribed with T7 or SP6 RNA polymerase, respectively, from PlAMV cDNA of its RdRp region (nucleotides 2,619 to 3,623 of pLi1) cloned into pGEM-5Zf(+) vectors (Promega Corp., Madison, WI, U.S.A.). A DIG-labeled, complementary RNA probe, corresponding to a fragment of the HEL sequence (nucleotides 1,299 to 2,829 of pLi1), was used to detect HEL mRNA.

Real-time PCR was performed as described by Komatsu and associates (2010), with PlAMV RNA values normalized relative to the values of EFIA.

\section{Protein analysis and immunoblotting.}

For detection of PlAMV-RdRp, agroinfiltrated areas of $N$. benthamiana leaves $(0.4 \mathrm{~g})$ were first homogenized in liquid nitrogen and then in $0.6 \mathrm{ml}$ of buffer $\mathrm{A}(50 \mathrm{mM}$ Tris- $\mathrm{HCl}, \mathrm{pH}$ 7.5; $15 \mathrm{mM} \mathrm{MgCl} ; 120 \mathrm{mM} \mathrm{KCl} ; 0.1 \%$ 2-mercaptoethanol; and $20 \%$ glycerol) containing a protease inhibitor cocktail (complete mini: Roche, one tablet per $25 \mathrm{ml}$ ). The homogenate was centrifuged at $1,000 \times g$ for $10 \mathrm{~min}$ at $4^{\circ} \mathrm{C}$ to remove cell debris, followed by $30,000 \times g$ for $30 \mathrm{~min}$ at $4^{\circ} \mathrm{C}$ to generate the supernatant fraction (S30) and the membrane-containing pellet fraction (P30). The P30 was dissolved in buffer A and subjected to sodium dodecyl sulfate polyacrylamide gel electrophoresis, followed by Western blotting. A rabbit polyclonal anti-RdRp antibody (further described in the Results section) diluted to $1 / 1,000$, or rabbit monoclonal anti-c-myc antibody (Cell Signaling Technology, Danvers, MA, U.S.A.) diluted to $1 / 1,500$, was used as the primary antibody. An anti-rabbit immunoglobulin $\mathrm{G}$ horseradish peroxidase-linked antibody (GE Healthcare, Piscataway, NJ, U.S.A.), diluted to $1 / 3,000$, was used as the secondary antibody. Detection was conducted using ECL Plus Western blotting detection reagents (GE Healthcare).

\section{Virus-induced gene silencing and cell death assays.}

Silencing of NbSGT1 and NbMAPKKK $\alpha$ was performed as described by Komatsu and associates (2010). After 2 to 3 weeks, the upper leaves of the silenced $N$. benthamiana plants were used for agroinfiltration assays. DAB staining and ion leakage assays of agroinfiltrated leaves also followed the methods described by Komatsu and associates (2010).

\section{ACKNOWLEDGMENTS}

We thank N.-H. Chua for providing the vector pER8 and D. Baulcombe for Tobacco rattle virus vector and silencing suppressor p19 gene. This work was supported by grants-in-aid from the Japan Society for the Promotion of Science and, in part, by a Grant-in-Aid for JSPS Fellows, and by the Program for Promotion of Basic Research Activities for Innovative Bioscience.

\section{LITERATURE CITED}

Abbink, T. E. M., Tjernberg, P. A., Bol, J. F., and Linthorst, H. J. M. 1998 Tobacco mosaic virus helicase domain induces necrosis in $\mathrm{N}$-gene carrying tobacco in the absence of virus replication. Mol. Plant-Microbe Interact. 11:1242-1246.

Atsumi, G., Kagaya, U., Kitazawa, H., Nakahara, K. S., and Uyeda, I. 2009. Activation of the salicylic acid signaling pathway enhances Clover yellow vein virus virulence in susceptible pea cultivars. Mol. PlantMicrobe Interact. 22:166-175.

Bamunusinghe, D., Hemenway, C. L., Nelson, R. S., Sanderfoot, A. A., Ye, C. M., Silva, M. A. T., Payton, M., and Verchot-Lubicz, J. 2009. Analysis of Potato virus $X$ replicase and TGBp3 subcellular locations. Virology 393:272-285.

Baurés, I., Candresse, T., Leveau, A., Bendahmane, A., and Sturbois, B. 2008. The $R x$ gene confers resistance to a range of Potexviruses in transgenic Nicotiana plants. Mol. Plant-Microbe Interact. 21:1154-1164.

Bendahmane, A., Kanyuka, K., and Baulcombe, D. C. 1999. The Rx gene from potato controls separate virus resistance and cell death responses. Plant Cell 11:781-792.

Burgyán, J., Hornyik, C., Szittya, G., Silhavy, D., and Bisztray, G. 2000. The ORF1 products of tombusviruses play a crucial role in lethal necrosis of virus-infected plants. J. Virol. 74:10873-10881.

Candresse, T., Marais, A., Faure, C., Dubrana, M. P., Gombert, J., and Bendahmane, A. 2010. Multiple coat protein mutations abolish recognition of Pepino mosaic potexvirus (PepMV) by the potato $R x$ resistance gene in transgenic tomatoes. Mol. Plant-Microbe Interact. 23:376-383.

Caplan, J. L., Mamillapalli, P., Bursh-Smith, T. M., Czymmek, K., and Dinesh-Kumar, S. P. 2008. Chloroplastic protein NRIP1 mediates innate immune receptor recognition of a viral effector. Cell 132:449-462.

Carette, J. E., van Lent, J., MacFarlane, S. A., Wellink, J., and van Kammen, A. 2002. Cowpea mosaic virus 32- and 60-kilodalton replication proteins target and change the morphology of endoplasmic reticulum membranes. J. Virol. 76:6293-6301.

Ehrenfeld, N., Cañón, P., Stange, C., Medina, C., and Arce-Johnson, P. 2005. Tobamovirus coat protein CPCg induces an HR-like response in sensitive tobacco plants. Mol. Cells 19:418-427. 
Erickson, F. L., Holzberg, S., Calderon-Urrea, A., Handley. V., Axtell, M., Corr, C., and Baker, B. 1999. The helicase domain of the TMV replicase proteins induces the $N$-mediated defence response in tobacco. Plant J. 18:67-75

Fellers, J. P., Tremblay, D., Handest, M. F., and Lommel, S. A. 2002. The Potato virus Y MSNR NIb-replicase is the elicitor of a veinal necrosishypersensitive response in root knot nematode resistant tobacco. Mol. Plant Pathol. 3:145-152.

Fernandez, I., Candresse, T., Gall, O. L., and Dunez, J. 1999. The 5' noncoding region of grapevine chrome mosaic nepovirus RNA-2 triggers a necrotic response on three Nicotiana spp. Mol. Plant-Microbe Interact. $12: 337-344$

Gallie, D. R. 1998. A tale of two termini: a functional interaction between the termini of an mRNA is a prerequisite for efficient translation initiation. Gene 216:1-11.

Gilardi, P., García-Luque, I., and Serra, M. T. 2004. The coat protein of tobamovirus acts as elicitor of both $L^{2}$ and $L^{4}$ gene-mediated resistance in Capsicum. J. Gen. Virol. 85:2077-2085.

Goulden, M. G., Kohm, B. A., Cruz, S. S., Kavanagh, T. A., and Baulcombe, D. C. 1993. A feature of the coat protein of potato virus X affects both induced virus resistance in potato and viral fitness. Virology 197:293302.

Hajimorad, M. R., Eggenberger, A. L., and Hill, J. H. 2005. Loss and gain of elicitor function of Soybean mosaic virus G7 provoking Rsv1-mediated lethal systemic hypersensitive response maps to P3. J. Virol. 79:1215-1222.

Hajimorad, M. R., Eggenberger, A. L., and Hill, J. H. 2006. Strain-specific P3 of Soybean mosaic virus elicits Rsv1-mediated extreme resistance, but absence of $\mathrm{P} 3$ elicitor function alone is insufficient for virulence on Rsv1-genotype soybean. Virology 345:156-166.

Han, Y. T., Tsai, C. S., Chen, Y. C., Lin, M. K., Hsu, Y. H., and Meng, M. 2007. Mutational analysis of a helicase motif-based RNA 5'-triphosphatase/NTPase from bamboo mosaic virus. Virology 367:41-50.

Kagiwada, S., Yamaji, Y., Komatsu, K., Takahashi, S., Mori, T., Hirata, H., Suzuki, M., Ugaki, M., and Namba S. 2005. A single amino acid residue of RNA-dependent RNA polymerase in the Potato virus $X$ genome determines the symptoms in Nicotiana plants. Virus Res. 110:177-182.

Kakizawa, S., Oshima, K., Kuboyama, T., Nishigawa, H., Jung, H. Y., Sawayanagi, T., Tsuchizaki, T., Miyata, S., Ugaki, M., and Namba, S. 2001. Cloning and expression analysis of Phytoplasma protein translocation genes. Mol. Plant-Microbe Interact. 14:1043-1050.

Kang, B. C., Yeam, I., and Jahn, M. M. 2005. Genetics of plant virus resistance. Annu. Rev. Phytopathol. 43:581-621.

Kim, B., Masuta, C., Matsuura, H., Takahashi, H., and Inukai, T. 2008 Veinal necrosis induced by Turnip mosaic virus infection in Arabidopsis is a form of defense response accompanying HR-like cell death. Mol. Plant-Microbe Interact. 12:260-268.

Kim, C. H., and Palukaitis, P. 1997. The plant defense response to cucumber mosaic virus in cowpea is elicited by the viral polymerase gene and affects virus accumulation in single cells. EMBO (Eur. Mol. Biol. Organ.) J. 16:4060-4068.

Király, L., Cole, A. B., Bourque, J. E., and Schoelz, J. E. 1999. Systemic cell death is elicited by the interaction of a single gene in Nicotiana clevelandii and gene VI of Cauliflower mosaic virus. Mol. Plant-Microbe Interact. 12:919-925.

Komarova, T. V., Skulachev, M. V., Zvereva, A. S., Schwartz, A. M., Dorokhov, Y. L., and Atabekov, J. G. 2006. New viral vector for efficient production of target proteins in plants. Biochemistry (Moscow) $71: 846-850$

Komatsu, K., Yamaji, Y., Ozeki, J., Hashimoto, M., Kagiwada, S., Takahashi, S., and Namba, S. 2008. Nucleotide sequence analysis of seven Japanese isolates of Plantago asiatica mosaic virus (PlAMV): a unique potexvirus with significantly high genomic and biological variability within the species. Arch. Virol. 153:193-198.

Komatsu, K., Hashimoto, M., Ozeki, J., Yamaji, Y., Maejima, K., Senshu, H., Himeno, M., Okano, Y., Kagiwada, S., and Namba, S. 2010. Viralinduced systemic necrosis in plants involves both programmed cell death and the inhibition of viral multiplication, which are regulated by independent pathways. Mol. Plant-Microbe Interact. 23:283-293.

Liu, L., Westler, W. M., den Boon, J. A., Wang, X., Diaz, A., Steinberg, H. A., and Ahlquist, P. 2009. An amphipathic $\alpha$-helix controls multiple roles of brome mosaic virus protein 1a in RNA replication complex assembly and function. PLoS Pathog. 5(3):e1000351.

Longstaff, M., Brigneti, G., Boccard, F., Chapman, S., and Baulcombe, D.
C. 1993. Extreme resistance to potato virus X infection in plants expressing modified components of the putative viral replicase. EMBO (Eur. Mol. Biol. Organ.) J. 12:379-386.

Martelli, G. P., Adams, M. J., Kreuze, J. F., and Dolja, V. V. 2007. Family Flexiviridae: a case study in virion and genome plasticity. Annu. Rev. Phytopathol. 45:4.1-4.28

Mochizuki, T., Hirai, K., Kanda, A. Ohnishi, J., Ohki, T., and Tsuda, S. 2009. Induction of necrosis via mitochondrial targeting of Melon necrotic spot virus replication protein p29 by its second transmembrane domain. Virology 390:239-249.

Ozeki, J., Takahashi, S., Komatsu, K., Kagiwada, S., Yamashita, K., Mori, T., Hirata, H., Yamaji, Y., Ugaki, M., and Namba, S. 2006. A single amino acid in the RNA-dependent RNA polymerase of Plantago asiatica mosaic virus contributes to systemic necrosis. Arch. Virol. 151:2067-2075.

Ozeki, J., Hashimoto, M., Komatsu, K. Maejima, K., Himeno, M., Senshu, H., Kawanishi, T., Kagiwada, S., Yamaji, Y., and Namba, S. 2009. The $\mathrm{N}$-terminal region of the Plantago asiatica mosaic virus coat protein is required for cell-to-cell movement but is dispensable for virion assembly. Mol. Plant-Microbe Interact. 22:677-685.

Palanichelvam, K., Cole, A. B., Shababi, M., and Schoelz, J. E. 2000. Agroinfiltration of Cauliflower mosaic virus gene VI elicits hypersensitive response in Nicotiana species. Mol. Plant-Microbe Interact. 11:1275-1279.

Rairdan, G. J., and Moffett, P. 2006. Distinct domains in the ARC region of the potato resistance protein Rx mediate LRR binding and inhibition of activation. Plant Cell 18:2082-2093.

Salánki, K., Gellért, Á., Náray-Szabó, G., and Balázs, E. 2007. Modelingbased characterization of the elicitor function of amino acid 461 of $\mathrm{Cu}$ cumber mosaic virus 1a protein in the hypersensitive response. Virology $358: 109-118$

Schaad, M. C., Jensen, P. E., and Carrington, J. C. 1997. Formation of plant RNA virus replication complexes on membranes: role of an endoplasmic reticulum-targeted viral protein. EMBO (Eur. Mol. Biol. Organ.) J. 16:4049-4059.

Senshu, H., Ozeki, J., Komatsu, K., Hashimoto, M., Hatada, K., Aoyama, M., Kagiwada, S., Yamaji, Y., and Namba, S. 2009. Variability in the level of RNA silencing suppression caused by triple gene block protein 1 (TGBp1) from various potexviruses during infection. J. Gen. Virol. 90:1014-1024.

Seo, J. K., Lee, S. H., and Kim, K. H. 2009. Strain-specific cylindrical inclusion protein of Soybean mosaic virus elicits extreme resistance and a lethal systemic hypersensitive response in two resistant soybean cultivars. Mol. Plant-Microbe Interact. 22:1151-1159.

Seo, Y. S., Rojas, M. R., Lee, J. Y., Lee, S. W., Jeon, J. S., Ronald, P., Lucas, W. J., and Gilbertson, R. L. 2006. A viral resistance gene from common bean functions across plant families and is up-regulated in a non-virus-specific manner. Proc. Natl. Acad. Sci. U.S.A. 103:1185611861.

Soosaar, J. L. M., Burch-Smith, T. M., and Dinesh-Kumar, S. P. 2005. Mechanisms of plant resistance to viruses. Nat. Rev. Microbiol. 3:789798.

Takahashi, S., Komatsu, K., Kagiwada, S., Ozeki, J., Mori, T., Hirata, H., Yamaji, Y., Ugaki, M., and Namba, S. 2006. The efficiency of interference of Potato virus $X$ infection depends on the target gene. Virus Res. $115: 214-217$

Taraporewala, Z., and Culver, J. N. 1996. Identification of an elicitor active site within the three-dimensional structure of the tobacco mosaic tobamovirus coat protein. Plant Cell 8:169-178.

Xu, P., and Roossinck, M. J. 2000. Cucumber mosaic virus D satellite RNA-induced programmed cell death in tomato. Plant Cell 12:10791092

Yamaji, Y., Kagiwada, S., Nakabayashi, H., Ugaki, M., and Namba, S. 2001. Complete nucleotide sequence of Tulip virus X (TVX-J): the border between species and strains within the genus Potexvirus. Arch. Virol. 146:2309-2320.

Zelenina, D. A., Kulaeva, O. I., Smirnyagina, E. V., Solovyev, A. G., Miroshnichenko, N. A., Fedorkin, O. N., Rodionova, N. P., Morozov, S. Y., and Atabekov, J. G. 1992. Translation enhancing properties of the 5 '-leader of potato virus X genomic RNA. FEBS (Fed. Eur. Biochem. Soc.) Lett. 296:267-270.

Zuo, J., Niu, Q. W., and Chua, N. H. 2000. An estrogen receptor-based transactivator XVE mediates highly inducible gene expression in transgenic plants. Plant J. 24:265-273. 